ORIGINAL ARTICLE

\title{
Lower respiratory tract illness and RSV prophylaxis in very premature infants
}

\author{
T Lacaze-Masmonteil, P Truffert, D Pinquier, P Daoud, G Goldfarb, E Vicaut, B Fauroux
}

Arch Dis Child 2004;89:562-567. doi: 10.1136/adc.2003.028282

See end of article for authors' affiliations ....................

Correspondence to: Dr T Lacaze-Masmonteil, Service de Réanimation et Pédiatrie Néonatales Hôpital, Antoine Béclère, Assistance Publique-Hôpitaux de Paris, 157 rue de la Porte de Trivaux, 92141 Clamart, France; tlacaze@club-internet.fr Accepted 5 September 2003

\begin{abstract}
Aims: To determine the frequency of and the risk factors for readmissions for any lower respiratory tract illness (LRTI) and for respiratory syncytial virus (RSV) documented LRTI in children born very prematurely who had or had not received RSV prophylaxis.

Methods: Multicentre prospective longitudinal cohort study of 2813 infants, born between April 2000 and December 2000 at less than 33 weeks of gestational age, and followed until the end of the epidemic season.

Results: Among the 2256 children who had no bronchopulmonary dysplasia at 36 weeks of postmenstrual age and were not submitted to RSV prophylaxis, $27.4 \%$ were readmitted at least once for any reason during the epidemic season; $15.1 \%$ and $7.2 \%$ were readmitted at least once for any LRTI and RSV related LRTI, respectively. Children born at less than 31 weeks' gestation, having an intrauterine growth restriction, or living in a single mother family were at a significantly higher risk of readmission for LRTI in general as well as for RSV related LRTI. Of the 376 children submitted to prophylaxis, $28.2 \%$ were readmitted at least once for any LRTI and $6.1 \%$ for RSV related LRTI.

Conclusion: One out of four children who had received no prophylaxis, was born very prematurely, and was without bronchopulmonary dysplasia at 36 weeks of postmenstrual age, was readmitted at least once for any reason. Roughly $50 \%$ and $20 \%$ of these readmissions were related to a LRTI and an RSV infection, respectively. Further epidemiological studies are warranted to assess the aetiology and impact of other respiratory pathogens on post-discharge readmission and respiratory morbidity in this population.
\end{abstract}

Each of the 61 centres was approached; 39 centres elected to participate. Seven secondary level care centres located in the Parisian area also participated in the study. Twenty one of the 23 regions were represented and all the tertiary level care centres of 12 regions and at least half of the centres in seven other regions participated in the survey. A telephone conference was organised with the primary physician of each participating centre by the independent monitoring centre to review the protocol and the case report form. Each case report form was tracked and entered into the database. Queries were established for all incomplete case report forms and incoherent data; answers to queries were recorded via telephone. An audit of several randomly selected centres was performed to verify data source and extent of data collection.

Hospital respiratory outcomes were recorded until the discharge from neonatal care or death of the patient.

The following birth related respiratory risk factors were assessed for all patients: gestational age, birth weight, intrauterine growth restriction (defined as birth weight below 10th centile), ${ }^{16}$ gender, out/inborn birth, singleton/ multiple pregnancy, bronchopulmonary dysplasia (BPD), defined as supplemental oxygen and/or ventilatory support requirement at either 28 days postnatal age or 36 weeks postmenstrual age, and postnatal age at discharge.

Each local investigator collected follow up data until April 2001 in the course of a visit to the hospital or through a phone conversation with the parents. The completed case report forms were sent to the CRO and entered in the database.

Abbreviations: RSV, respiratory syncytial virus; LRTI, lower respiratory tract illness; BPD, bronchopulmonary dysplasia; NICU, neonatal intensive care unit; $\mathrm{PICU}$, pediatric intensive care unit 
The following demographic risk factors were also assessed: number of school age siblings at home, tobacco smoke exposure, and single mother family. For patients who received prophylaxis with palivizumab (Synagis, Abbott Laboratories), the dates of administration and the number of doses were also recorded. For all patients readmitted between initial hospital discharge and April 2001, the following data were collected: date, cause and duration of hospitalisation, RSV status-assessed at admission by immunofluorescence on nasopharyngeal aspirates ${ }^{17}$-in case of hospitalisation for LRTI, and duration of supplemental oxygen therapy and/or mechanical ventilation if required.

\section{Statistical analysis}

For infants discharged after their initial hospitalisation, outcomes (readmissions and diagnosis) were first compared according to whether the children did or did not receive prophylaxis with palivizumab. In order to identify potential independent predictors of hospitalisation in children who did not receive prophylaxis, a two step procedure was used.

First, univariate analyses were carried out to screen for potential predictors and to reduce the number of variables entered in the multivariate model (screening procedure). Then, a stepwise Cox's analysis was performed to identify the independent predictors of hospitalisation for LRTI in general and RSV related LRTI. A survival model was chosen over a classic logistic regression model, because it takes into account the time period between initial hospital discharge and the end of the epidemic season (April 2001) for each patient and thereby includes an adjustment on the effective period of exposure. Because the majority of children with BPD at 36 weeks of postmenstrual age received palivizumab prophylaxis, thereby precluding any assessment of the relation between this variable and the risk of RSV related hospitalisation, the risk factors analyses were performed in the population of children who did not receive prophylaxis and were without BPD at 36 weeks of postmenstrual age.

All quantitative data were presented as mean and 95\% two sided confidence interval (CI). For qualitative and ordinal variables, the frequency of each category, odds ratio, and associated 95\% CI were calculated. Univariate analyses were carried out using Student's $t$ test for quantitative variables, and Pearson's $\chi^{2}$ test was used for quantitative or ordinal variables. All $\mathrm{p}$ values were based on two sided tests. Statistical significance was fixed at 5\%. Univariate and multivariate analyses were performed with SAS statistical software, version 8 (SAS Institute, Cary, NC).

\section{RESULTS}

\section{Characteristics of the cohort}

A total of 3636 infants, with a gestational age of 23-32 weeks, were consecutively admitted into one of the 46 participating centres and enrolled in the survey. Four hundred and six infants $(11.2 \%)$ died in the course of their NICU stay and 88 infants were still in the neonatal care at the end of the observation period (April 2001). Among the 3142 children who were discharged between April 2000 and April 2001, 2813 children (89.5\%) were followed until April 2001. Table 1 shows the clinical characteristics of these patients and those infants lost to follow up.

Children lost to follow up were significantly more mature and more often issued from a single pregnancy. They were also less likely to have BPD at 28 days of postnatal age or 36 weeks of postmenstrual age.

Of the 2813 followed children, 17 children $(0.6 \%)$ died after discharge. Two of these 17 deaths ( $12 \%)$ were related to RSV infection; both occurred in patients who did not receive RSV prophylaxis. Three hundred and seventy six children
(13.4\%) received at least one dose of palivizumab, whereas 2370 children $(84.3 \%)$ did not.

Whether at least one dose of palivizumab was administered during the study period remained uncertain in 67 patients. There were significant differences in the distribution of date of discharge, gestational age, birth weight, and BPD rate between the groups who did and did not receive prophylaxis. Patients who received prophylaxis were significantly more premature, had a higher incidence of $\mathrm{BPD}$, and were more frequently discharged at the onset of the epidemic season (table 2).

\section{Rates of hospitalisation in the cohort and risk factors for hospitalisation}

During the study period, readmissions to hospital for any reason were recorded for all 2813 children. Eight hundred and thirty children (29.5\%) required a total of 1171 hospitalisations. Among these 830 children, 231 (27.8\%) required more than one hospitalisation. Each hospitalised infant required an average of 1.4 readmissions. Four hundred sixty nine children (16.7\%) and 197 children $(7.0 \%)$ were hospitalised at least once for an LRTI in general and a RSV documented LRTI, respectively.

The following analysis was restricted to the 2256 untreated children without BPD at 36 weeks of postmenstrual age. Among these children, 264 infants (11.7\%) had BPD at 28 days of postnatal age. Nine children $(0.4 \%)$ died after discharge during the study period. Six hundred and seventeen children $(27.4 \%)$ were readmitted at least once for any reason and 340 children (15.1\%) were readmitted at least once for an LRTI. One hundred and sixty three children $(7.2 \%)$ and 129 children $(5.7 \%)$ required at least one readmission for RSV documented and RSV negative LRTI, respectively. Seventy four children $(3.3 \%)$ were readmitted for LRTI without RSV testing. Thirty one children required at least two LRTI related readmissions with a different RSV status. A total of 833 readmissions were necessary in the 617 children, and 157 children required more than one readmission. Four hundred and seven of the 833 hospitalisations $(48.9 \%)$ were associated with an LRTI; RSV was documented in $169(41.5 \%)$ of these 407 LRTI related hospitalisations. Nine children ( $0.4 \%$ of the cohort) required mechanical ventilation during their RSV related hospitalisation and one death related to RSV was observed in a child with mild BPD born at 29 weeks' gestation. The median length of RSV related hospital stay was 7 days (range 1 to $30)$.

There was a significant association between hospitalisation for any LRTI on the one hand and both gestational age and birth weight on the other hand (table 3 ). In the univariate analysis, additional factors associated with a higher rate of hospitalisation for LRTI were: singleton pregnancy, living at home with siblings, having a smoking mother, and living in a single mother family. Stepwise multivariate Cox's analyses with adjustment for the age at the onset of exposure were performed to assess the relation between hospitalisation and all the birth related and demographic respiratory risk factors. Singleton pregnancy (OR 1.5; 95\% CI 1.1 to 2.0; p < 0.01), a birth before 31 weeks' gestation (OR 1.6; 95\% CI 1.3 to 2.0; $\mathrm{p}<0.001$ ), intrauterine growth restriction (OR 1.7; 95\% CI 1.2 to $2.5 ; \mathrm{p}<0.01$ ), a single mother family (OR $1.8 ; 95 \% \mathrm{CI}$ 1.3 to $2.7 ; \mathrm{p}<0.01)$, and the presence of siblings at home (OR $1.8 ; 95 \%$ CI 1.4 to $2.3 ; \mathrm{p}<0.0001$ ), were all found to be significant independent predictors of hospitalisation for any LRTI.

An identical analysis was performed to assess the relation between these variables and the risk of hospitalisation for RSV related LRTI (table 4). Significant independent predictors of hospitalisation for RSV infection included: a birth 
Table 1 Characteristics of the cohort

\begin{tabular}{|c|c|c|c|c|c|c|c|}
\hline \multirow[b]{2}{*}{ Inborn*, no./total no. (\%) } & \multicolumn{2}{|c|}{$\begin{array}{l}\text { Children admitted to the } \\
\text { NICU at birth }(n=3636)\end{array}$} & \multicolumn{2}{|c|}{$\begin{array}{l}\text { Children followed beyond } \\
\text { April } 2001(n=2813)\end{array}$} & \multicolumn{2}{|c|}{$\begin{array}{l}\text { Children lost to } \\
\text { follow up }(n=329)\end{array}$} & \multirow{2}{*}{$\frac{\mathbf{p}}{0.34}$} \\
\hline & $2508 / 3630$ & (69.1) & $1987 / 2809$ & (70.7) & $223 / 327$ & (68.2) & \\
\hline Male gender ${ }^{*}$, no./total no. (\%) & $1993 / 3634$ & $(54.8)$ & $1549 / 2813$ & $(55.1)$ & $169 / 329$ & $(51.4)$ & 0.20 \\
\hline Single pregnancy*, no./total no. (\%) & $2516 / 3631$ & (69.3) & $1931 / 2810$ & (68.7) & $260 / 329$ & $(79.0)$ & 0.0001 \\
\hline Gestational age ${ }^{\star}$, total no. & 3632 & & 2809 & & 329 & & 0.13 \\
\hline $23-30$ wk, no. (\%) & 2053 & $(56.5)$ & 1489 & $(53.0)$ & 160 & $(48.6)$ & \\
\hline $31-32$ wk, no. (\%) & 1579 & $(43.5)$ & 1320 & $(47.0)$ & 169 & $(51.4)$ & \\
\hline Gestational age (wk), median (range) & 30 & $(23-32)$ & 30 & $(23-32)$ & 31 & $(24-32)$ & 0.003 \\
\hline Birth weight*, total no. & 3633 & & 2812 & & 329 & & 0.03 \\
\hline$<1000 \mathrm{~g}$, no. $(\%)$ & 890 & $(24.5)$ & 566 & $(20.1)$ & 46 & $(14.0)$ & \\
\hline $1000-1500 \mathrm{~g}$, no. $(\%)$ & 1537 & (42.3) & 1231 & $(43.8)$ & 152 & $(46.2)$ & \\
\hline$>1500 \mathrm{~g}, \mathrm{no} .(\%)$ & 1206 & (33.2) & 1015 & $(36.1)$ & 131 & $(39.8)$ & \\
\hline Birth weight $(\mathrm{g})$, mean (SD) & 1329 & $(409)$ & 1371 & (393) & 1427 & (373) & 0.01 \\
\hline Intrauterine growth restriction*, no./total no. (\%) & $339 / 3627$ & $(9.4)$ & $228 / 2808$ & $(8.1)$ & $20 / 328$ & (6.1) & 0.20 \\
\hline Supplemental $\mathrm{O}_{2}$ at 28 dayst, no./total no. (\%) & $792 / 3410$ & $(23.2)$ & $658 / 2799$ & $(23.5)$ & $44 / 321$ & (13.7) & $<0.0001$ \\
\hline Supplemental $\mathrm{O}_{2}$ at 36 weeks $\ddagger$, no./total no. (\%) & $307 / 3363$ & $(9.1)$ & $258 / 2789$ & $(9.2)$ & $11 / 316$ & $(3.5)$ & 0.0005 \\
\hline
\end{tabular}

at less than 31 weeks' gestation (OR 1.5; 95\% CI 1.1 to 2.2; $\mathrm{p}=0.01$ ), an intrauterine growth restriction (OR $1.7 ; 95 \%$ CI 1.0 to $3.0 ; p=0.05$ ), and a single mother family (OR $2.1 ; 95 \%$ CI 1.3 to $3.6 ; p<0.01)$. For infants with siblings at home, the trend was similar to the one observed for LRTI in general, although not statistically different (OR 1.4; 95\% CI 1.0 to 1.9 ; $\mathrm{p}=0.07)$. In children without BPD at 36 weeks of postmenstrual age, BPD at 28 days of age was not found to be an independent risk factor for hospitalisation either for LRTI in general, or for RSV documented LRTI.

\section{Effect of prophylaxis on rehospitalisation rates}

Infants who received RSV prophylaxis were more likely to be hospitalised at least once for any cause $(43.6 \%$ versus $27.4 \%$, $\mathrm{p}<0.0001)$, for LRTI in general $(28.2 \%$ versus $15.0 \%$, $\mathrm{p}<0.0001)$, and for non-RSV related LRTI $(21.3 \%$ versus $5.8 \%, \mathrm{p}<0.0001$ ) (table 2 ). In contrast, and despite being at a significantly higher respiratory risk, no increased rate of rehospitalisation for RSV related LRTI was observed in the children who received prophylaxis $(6.1 \%)$, compared to those who did not $(7.2 \%, \mathrm{p}=0.5)$ (table 2$)$. In the group that did not receive prophylaxis (878 hospitalisations), 427 (51.7\%) hospitalisations were due to LRTI in general. In the group that received prophylaxis (275 hospitalisations), 146 (53.1\%, $\mathrm{p}=0.2$ ) hospitalisations were due to LRTI in general. The rate of hospitalisation for RSV related infection was $20.1 \%$ in the non-prophylaxis group (176 among 878 hospitalisations), compared to $8.4 \%(\mathrm{p}<0.001)$ in the prophylaxis group $(23$ among 275 hospitalisations). Four children in the prophylaxis group were hospitalised for RSV related infection before the initiation of prophylaxis. Therefore, 19 hospitalisations for RSV related infection in the prophylaxis group occurred during the treatment period; this represented $8.0 \%$ of the total number of hospitalisations, compared to $20.1 \%$ in the

Table 2 Characteristics of the children according to prophylaxis

\begin{tabular}{|c|c|c|c|c|c|}
\hline \multirow[b]{2}{*}{ Inborn*, no./total no. (\%) } & \multicolumn{2}{|c|}{$\begin{array}{l}\text { No RSV prophylaxis } \\
(\mathrm{n}=2370)\end{array}$} & \multicolumn{2}{|c|}{$\begin{array}{l}\text { RSV prophylaxis } \\
(n=376)\end{array}$} & \multirow{3}{*}{$\begin{array}{l}\mathbf{p} \\
0.40\end{array}$} \\
\hline & $1668 / 2366$ & $(70.5)$ & $273 / 376$ & (72.6) & \\
\hline Male gender ${ }^{*}$, no./total no. (\%) & $1297 / 2370$ & (54.7) & $213 / 376$ & (56.7) & \\
\hline Single pregnancy*, no./total no. (\%) & $1615 / 2370$ & (68.1) & $269 / 373$ & (72.1) & 0.12 \\
\hline Gestational age ${ }^{*}$, total no. & 2366 & & 376 & & $<0.0001$ \\
\hline $23-30$ wk, no. (\%) & 1125 & (47.5) & 328 & (87.2) & \\
\hline $31-32$ wk, no. (\%) & 1241 & (52.5) & 48 & (12.8) & \\
\hline Gestational age (wk), median (range) & 31 & $(23-32)$ & 28 & $(24-32)$ & $<0.0001$ \\
\hline Birth weight*, total no. & 2370 & & 376 & & $<0.0001$ \\
\hline$<1000 \mathrm{~g}$, no. (\%) & 364 & (15.4) & 191 & $(50.8)$ & \\
\hline $1000-1500 \mathrm{~g}$, no. $(\%)$ & 1053 & (44.4) & 146 & (38.8) & \\
\hline$>1500 \mathrm{~g}$, no. $(\%)$ & 953 & (40.2) & 39 & (10.4) & \\
\hline Birth weight (g), mean (SD) & 1417 & (383) & 1071 & $(326)$ & $<0.0001$ \\
\hline Intrauterine growth restriction*, no./total no. (\%) & $184 / 2366$ & $(7.8)$ & $39 / 376$ & $(10.4)$ & 0.09 \\
\hline Supplemental $\mathrm{O}_{2}$ at 28 days*, no./total no. (\%) & $360 / 2359$ & (15.3) & $280 / 375$ & $(74.7)$ & $<0.0001$ \\
\hline Supplemental $\mathrm{O}_{2}$ at 36 weeks*, no./total no. (\%) & $97 / 2353$ & (4.1) & $154 / 371$ & (41.5) & $<0.0001$ \\
\hline Date of discharge*, total no. & 2370 & & 376 & & $<0.0001$ \\
\hline Before October 2000, no. (\%) & 1104 & $(46.6)$ & 139 & $(37.0)$ & \\
\hline October-December 2000, no. (\%) & 775 & (32.7) & 176 & (46.8) & \\
\hline After December 2000, no. (\%) & 491 & (20.7) & 61 & (16.2) & \\
\hline Age at the onset of exposure (wk), median (range) & 9.1 & $(0.1-38.1)$ & 13.3 & $(0.3-31.0)$ & $<0.0001$ \\
\hline $\begin{array}{l}\text { At least once hospitalised for any cause, no. (\%) } \\
\text { At least once hospitalised for LRI }\end{array}$ & $\begin{array}{l}650 \\
356\end{array}$ & $(27.4)$ & $\begin{array}{l}164 \\
106\end{array}$ & $(43.6)$ & $\begin{array}{l}<0.0001 \\
<0.0001\end{array}$ \\
\hline $\begin{array}{l}\text { At least once hospitalised for RSV related } \\
\text { infection, no. (\%) }\end{array}$ & 170 & $(7.2)$ & 23 & $(6.1)$ & 0.46 \\
\hline $\begin{array}{l}\text { At least once hospitalised for RSV negative LRI, } \\
\text { no. (\%) }\end{array}$ & 138 & (5.8) & 80 & (21.3) & $<0.0001$ \\
\hline
\end{tabular}




\begin{tabular}{|c|c|c|c|c|c|}
\hline & n/no. & $\%$ & Unad & d OR $(95 \% \mathrm{Cl})$ & p \\
\hline \multicolumn{6}{|l|}{ Inborn } \\
\hline No & $97 / 673$ & 14.4 & Ref & & \\
\hline Yes & $242 / 1579$ & 15.3 & 1.1 & 0.8 to 1.6 & 0.6 \\
\hline \multicolumn{6}{|l|}{ Gender } \\
\hline Female & $141 / 1027$ & 13.7 & Ref & & \\
\hline Male & $199 / 1229$ & 16.2 & 1.2 & 1.0 to 1.5 & 0.1 \\
\hline \multicolumn{6}{|l|}{ Pregnancy } \\
\hline Multiple & $91 / 720$ & 12.6 & Ref & & \\
\hline Singleton & $249 / 1536$ & 16.2 & 1.3 & 1.0 to 1.7 & $<0.05$ \\
\hline \multicolumn{6}{|l|}{ Gestational age } \\
\hline 31-32 weeks & $160 / 1220$ & 13.1 & Ref & & \\
\hline Less than 31 weeks & $180 / 1036$ & 17.4 & 1.4 & 1.1 to 1.8 & $<0.01$ \\
\hline \multicolumn{6}{|l|}{ Birth weight } \\
\hline More than $1500 \mathrm{~g}$ & $128 / 967$ & 13.2 & Ref & & \\
\hline $1000-1500 \mathrm{~g}$ & $160 / 1003$ & 16.0 & 1.3 & 1.0 to 1.6 & \\
\hline Less than $1000 \mathrm{~g}$ & $52 / 286$ & 18.2 & 1.5 & 1.1 to 2.1 & $<0.05$ \\
\hline \multicolumn{6}{|l|}{ Intrauterine growth restriction } \\
\hline No & $307 / 2083$ & 14.7 & Ref & & \\
\hline Yes & $33 / 169$ & 19.5 & 1.4 & 0.9 to 2.1 & 0.1 \\
\hline \multicolumn{6}{|l|}{ BPD at 28 days } \\
\hline No & $291 / 1992$ & 14.6 & Ref & & \\
\hline Yes & $49 / 264$ & 18.6 & 1.3 & 1.0 to 1.9 & 0.1 \\
\hline \multicolumn{6}{|l|}{ Siblings at home } \\
\hline No & $120 / 1054$ & 11.4 & Ref & & \\
\hline Yes & $219 / 1090$ & 18.4 & 1.8 & 1.4 to 2.2 & $<0.0001$ \\
\hline \multicolumn{6}{|l|}{ Maternal smoking } \\
\hline No & $258 / 1802$ & 14.3 & Ref & & \\
\hline Yes & $82 / 454$ & 18.1 & 1.3 & 1.0 to 1.7 & $<0.05$ \\
\hline \multicolumn{6}{|l|}{ Paternal smoking } \\
\hline No & $264 / 1737$ & 15.2 & Ref & & \\
\hline Yes & $76 / 519$ & 14.6 & 0.9 & 0.7 to 1.3 & 0.8 \\
\hline \multicolumn{6}{|l|}{ Monoparental (mother) family } \\
\hline No & $293 / 2028$ & 14.5 & Ref & & \\
\hline Yes & $33 / 129$ & 25.6 & 2.0 & 1.3 to 3.1 & $<0.0001$ \\
\hline \multicolumn{6}{|l|}{ Date of discharge } \\
\hline After December 2000 & $49 / 427$ & 11.5 & Ref & & \\
\hline Before October 2000 & $153 / 1080$ & 14.2 & 1.3 & 0.9 to 1.8 & \\
\hline October-December 2000 & $138 / 749$ & 18.2 & 1.7 & 1.2 to 2.5 & $<0.01$ \\
\hline \multicolumn{6}{|l|}{ Age at onset of exposure } \\
\hline More than 3 months & $82 / 607$ & 13.5 & Ref & & \\
\hline 3 months or less & $258 / 1649$ & 15.6 & 1.2 & 0.9 to 1.6 & 0.2 \\
\hline
\end{tabular}

non-prophylaxis group $(\mathrm{p}<0.001)$. Mechanical ventilation in a PICU was required for two of the 19 RSV documented hospitalisations $(10.5 \%)$ in the prophylaxis group and nine of the 176 RSV related hospitalisations (5.1\%) in the nonprophylaxis group. No RSV related deaths were observed in patients who received prophylaxis.

\section{DISCUSSION}

Based on recently published national perinatal data, ${ }^{18}$ it is estimated that around $50 \%$ of the total number of very premature infants born during the study period in France were enrolled. Most of the regions of the country, and therefore the corresponding climatic characteristics, were represented by at least one regional tertiary level for 20 of the 23 regions and all of the tertiary level care centres for 12 regions. Half of the centres of three predominantly urbanised regions with a high population density (Paris area, Nord-Pas de Calais, Rhone-Alpes) were represented.

The cohort consisted of infants born at the tertiary level care centre or admitted into the corresponding neonatal intensive care unit at birth. Exceptions included infants in seven secondary level care centres located in the Paris area.

These results need to be interpreted with regard to the limitation of the study. First, infants born at or admitted to a secondary level care centre, who were not subsequently transferred into a neonatal intensive care unit, were not enrolled in the survey. Consequently, an under-representation of infants with gestational age $>30$ weeks' gestation cannot be excluded, although the percentage of infants born at 31 and 32 weeks of gestation (19\% and 25\%, respectively) did not differ from the estimated percentage derived from a population based multiregional study performed in 1997. ${ }^{18}$ Second, children in the cohort lost to follow up before the end of the observational period represented $10.5 \%$ of the study cohort. These lost to follow up children were more mature and were less likely to have any form of BPD. Therefore, the risk of rehospitalisation for RSV documented infection calculated in the followed cohort may have been slightly overestimated.

In this survey, $13.4 \%$ of the children received at least one dose of palivizumab; these included those with the most severe disease. Most of the children who received prophylaxis were extremely premature; many had severe BPD with 41.5\% of them requiring either supplemental oxygen or ventilatory support at 36 weeks of postmenstrual age.

Assuming that prophylaxis reduced the rate of hospitalisation by $39 \%$ in those children, as has been observed for children with BPD in the IMpact RSV trial, ${ }^{13}$ the rate of hospitalisation for RSV related infection in the whole cohort in the absence of prophylaxis would have been $8.2 \%$. This latter rate is comparable to the rate of RSV related hospitalisation (7.3\%) identified by Joffe and colleagues, ${ }^{3}$ in a retrospective study in infants with similar neonatal characteristics. Finally, 3.7\% of the children hospitalised for a lower respiratory tract illness had no RSV testing, and the sensibility of the immunofluorescence assay used for the 
Table 4 Factors associated with RSV related LRTI: univariate analysis

\begin{tabular}{|c|c|c|c|c|c|}
\hline & n/no. & $\%$ & & $\mathrm{R}(95 \% \mathrm{Cl})$ & p \\
\hline \multicolumn{6}{|l|}{ Inborn } \\
\hline No & $46 / 673$ & 6.8 & Ref & & \\
\hline Yes & $116 / 1579$ & 7.4 & 1.1 & 0.8 to 1.5 & 0.7 \\
\hline \multicolumn{6}{|l|}{ Gender } \\
\hline Female & $65 / 1027$ & 6.3 & Ref & & \\
\hline Male & $98 / 1229$ & 8.0 & 1.3 & 0.9 to 1.8 & 0.1 \\
\hline \multicolumn{6}{|l|}{ Pregnancy } \\
\hline Multiple & $47 / 720$ & 6.5 & Ref & & \\
\hline Singleton & $116 / 1536$ & 7.6 & 1.2 & 0.8 to 1.7 & 0.4 \\
\hline \multicolumn{6}{|l|}{ Gestational age } \\
\hline $31-32$ weeks & $79 / 1220$ & 6.5 & Ref & & \\
\hline Less than 31 weeks & $84 / 1036$ & 8.1 & 1.3 & 0.9 to 1.8 & 0.1 \\
\hline \multicolumn{6}{|l|}{ Birth weight } \\
\hline More than $1500 \mathrm{~g}$ & $63 / 967$ & 6.5 & Ref & & \\
\hline $1000-1500 \mathrm{~g}$ & $73 / 1003$ & 7.3 & 1.1 & 0.8 to 1.5 & \\
\hline Less than $1000 \mathrm{~g}$ & $27 / 286$ & 9.4 & 1.6 & 1.0 to 2.5 & 0.1 \\
\hline \multicolumn{6}{|l|}{ Intrauterine growth restriction } \\
\hline No & $146 / 2083$ & 7.0 & Ref & & \\
\hline Yes & $17 / 169$ & 10.1 & 1.5 & 0.9 to 2.5 & 0.1 \\
\hline \multicolumn{6}{|l|}{ BPD at 28 days } \\
\hline No & $145 / 1992$ & 7.3 & Ref & & \\
\hline Yes & $18 / 264$ & 6.8 & 0.9 & 0.6 to 1.5 & 0.8 \\
\hline \multicolumn{6}{|l|}{ Siblings at home } \\
\hline No & $62 / 1054$ & 5.9 & Ref & & \\
\hline Yes & $100 / 1090$ & 8.4 & 1.5 & 1.1 to 2.0 & 0.02 \\
\hline \multicolumn{6}{|l|}{ Maternal smoking } \\
\hline No & $125 / 1802$ & 6.9 & Ref & & \\
\hline Yes & $38 / 454$ & 8.4 & 1.2 & 0.8 to 1.8 & 0.3 \\
\hline \multicolumn{6}{|l|}{ Paternal smoking } \\
\hline No & $129 / 1737$ & 7.4 & Ref & & \\
\hline Yes & $34 / 519$ & 6.6 & 0.9 & 0.6 to 1.3 & 0.5 \\
\hline \multicolumn{6}{|l|}{ Monoparental (mother) family } \\
\hline No & $139 / 2028$ & 6.9 & Ref & & \\
\hline Yes & $17 / 129$ & 13.2 & 2.1 & 1.2 to 3.5 & $<0.01$ \\
\hline \multicolumn{6}{|l|}{ Date of discharge } \\
\hline After December 2000 & $15 / 427$ & 3.5 & Ref & & \\
\hline Before October 2000 & $75 / 1080$ & 6.9 & 2.0 & 1.2 to 3.6 & \\
\hline October-December 2000 & $73 / 749$ & 9.7 & 3.0 & 1.7 to 5.2 & $<0.001$ \\
\hline \multicolumn{6}{|l|}{ Age at onset of exposure } \\
\hline More than 3 months & $33 / 607$ & 5.4 & Ref & & \\
\hline 3 months or less & $130 / 1649$ & 7.9 & 1.5 & 1.0 to 2.2 & $<0.05$ \\
\hline
\end{tabular}

identification of RSV in nasopharyngeal aspirations exceeds $95 \%$ but does not reach $100 \% .{ }^{17}$ These two factors may also contribute to a slight underestimation of the rate of RSV related hospitalisation in these patients.

In 1999, the French Paediatric Society issued guidelines for the use of RSV prophylaxis with palivizumab, limiting it to children: either (1) less than 6 months old at the onset of RSV epidemic season, born prematurely at 32 weeks' gestation or less, with a history of BPD at 28 days of postnatal age; or (2) under 2 years of age, born prematurely at 35 weeks' gestation or less, with a history of BPD, and receiving a long term treatment at the onset of the RSV epidemic season. The present study was performed one year after the issue of these guidelines and shows that physicians were more restrictive in their indications for children less than 6 months old and limited the use of RSV prophylaxis to the most premature infants with severe BPD. In agreement with previous retrospective and prospective studies, this study also supports that, in children without BPD at 36 weeks of postmenstrual age, gestational age is a strong independent risk factor for admission due to RSV infection. ${ }^{3-5}$ 8-10 In addition, there was a trend, although not statistically significant, in favour of a higher risk of hospitalisation for RSV related infection in children with school age siblings at home. ${ }^{49}$ Intrauterine growth restriction has been previously found to be associated with a higher risk of BPD in very premature infants. ${ }^{19}$ Small for gestational age infants have also been reported to have a higher rate of post-neonatal morbidity with an increased risk of readmission to hospital during the first year of life. ${ }^{2021}$ As for appropriate for gestational age infants without BPD at 36 weeks of postmenstrual age, the main cause of rehospitalisation in small for gestational age infants was LRTI. A new independent risk factor not hitherto identified was living in a single mother family. Infants living in a single mother family represented a small fraction of our cohort $(8 \%)$, but this social factor was associated with a very high risk of rehospitalisation for both LRTI $(25.6 \%)$ in general and RSV related LRTI (13.2\%). In children without BPD at 36 weeks of postmenstrual age, the need for either supplemental oxygen or ventilatory support at 28 days of postnatal age was not found to be a significant predictor of hospitalisation for either LRTI in general or RSV related LRTI. This unexpected finding suggests that BPD at 28 days of age is a less pertinent predictive factor than other factors such as extremely low gestational age, intrauterine growth restriction, siblings at home, and single mother family.

Forty one percent of the total number of hospitalisations for LRTI in infants who did not receive prophylaxis was attributable to RSV. In agreement with several previous incidence studies, ${ }^{22}$ RSV infected children accounted for $40-$ $60 \%$ of the total number of children hospitalised for LRTI in each subgroup of the stratified analysis (tables 3 and 4). In contrast, among infants who received prophylaxis, RSV documented hospitalisations accounted for only $16 \%$ of the total number of hospitalisations due to an LRTI. This finding supports the preventive benefit of palivizumab in this population. Nevertheless, our results show that very premature 
infants remain at high risk of hospitalisations for LRTI in general. The prevention of other common respiratory infection caused by influenzae virus, parainfluenzae virus, and rhinovirus represents a real challenge. ${ }^{123}$ The efficacy and safety of influenzae vaccine in this age group remains to be evaluated. Rhinovirus, which is more difficult to identify routinely, seems to be more common than previously expected and has recently been shown to increase the severity of an RSV infection. ${ }^{24}$ In conclusion, this study emphasises the impact of the birth related factors on readmission rates. Home related environmental and social risk factors are difficult to control and parent information and education remain essential.

Finally, studies on respiratory infections other than RSV and new preventive therapeutic options are currently warranted in these high risk children.

\section{ACKNOWLEDGEMENTS}

The study was funded by Abbott France. The monitoring and the database management were performed by a CRO, Mediscan (Marc Childs). We thank J Groothuis, MD, L Foix-L'Hélias, MD, and T Klassen, MD, for their valuable advice. The PrimeVeRes study group consisted of A Rousset (Montreuil); AC Mouries-Perier, (Toulouse), H Razafimahefa (Clamart), JM Hascoet, (Nancy), F Boubred (Marseille), JF Magny (Paris), JC Rozé (Nantes), PL Sann, (Lyon), $\mathrm{R}$ Lenclen (Poissy), C Elleau and J Sarlangue (Bordeaux), C Fromentin (Besançon), Y Aujard (Paris), V Tessier (Tours), G Diene (Rouen), O Claris (Lyon), B Roméo (Amiens), C Fichtner (SaintEtienne), J Leraillez (Pontoise), M Ayass (Orléans), D Amram (Nimes), I Petit (Clermont-Ferrand), B Guillois (Caen), P Kuhn and J Beladdale (Strasbourg), A Anton and JL Bessis (Cherbourg), F Malot and C Dufour (Reims), C Palix, (Marseille), V Mucignat (Paris), A Dubois (Calais), B Thelliez (Lens), F Beringue and S Lebouedec (Angers), A Nassimi, (Poitiers), D Ronayette (Limoges), F Gold (Paris), C Allisy (Argenteuil), RP Dupuy (Saint-Brieuc), B Delaporte (Le Havre), JM Bonardi (Le Mans), A Goldfarb (Vannes), C Lejeune (Colombes), T Mansir (Pau), D Mitanchez (Paris), M Granier (Evry), K Alissa (Fontainebleau), JC Ropert (Neuilly), S Langlais (Montereau), D Duprez (Villeneuve-Saint-Georges), C de Gennes (Orsay).

\section{Authors' affiliations}

T Lacaze-Masmonteil, Hôpital Antoine-Béclère, Assistance PubliqueHôpitaux de Paris, Clamart, France

P Truffert, Centre Hospitalier Universitaire, Jeanne de Flandre, Lille, France

D Pinquier, Centre Hospitalier Universitaire, Roven, France

P Daoud, Centre Hospitalier Intercommunal, Montreuil, France

G Goldfarb, Laboratoire Abbott France

E Vicaut, Hôpital Lariboisière, Assistance Publique-Hôpitaux de Paris, Paris, France

B Fauroux, Hôpital Armand-Trousseau, INSERM E0213, Assistance

Publique-Hôpitaux de Paris, Paris, France

\section{REFERENCES}

1 Hall CB. Respiratory syncytial virus and parainfluenza virus. N Engl J Med 2001;344:1917-28.

2 Shay DK, Holman RC, Newman RD, et al. Bronchiolitis-associated hospitalizations among US children, 1980-1996. JAMA 1999;282:1440-6.

3 Joffe S, Escobar GJ, Black SB, et al. Rehospitalization for respiratory syncytial virus among premature infants. Pediatrics 1999;104:894-9.

4 Boyce TG, Mellen BG, Mitchel EF, et al. Rates of hospitalization for respiratory syncytial virus infection among children in Medicaid. J Pediatr 2000;137:865-70.

5 Stevens TP, Sinkin RA, Hall CB, et al. Respiratory syncytial virus and premature infants born at 32 weeks' gestation or earlier. Arch Pediatr Adolesc Med 2000;154:55-61

6 Cunningham CK, MCMillan JA, Gross SJ. Rehospitalization for respiratory illness in infants less than 32 weeks' gestation. Pediatrics 1991;88:527-32.

7 Yuksel B, Greenough A. Birth weight and hospital readmission of infants born prematurely. Arch Pediatr Adolesc Med 1994;148:384-8.

8 Nachman S, Navaie-Waliser M, Qureshi M. Rehospitalization with respiratory syncytial virus after neonatal intensive care unit discharge: a 3year follow-up. Pediatrics 1997;100(6)

9 Carbonnel-Estrany X, Quero J, Bustos G, et al. Rehospitalization because of respiratory syncytial virus infection in premature infants younger than 33 weeks of gestation : a prospective study. Pediatr Infect Dis J 2000;19:592-7.

10 Carbonnel-Estrany X, Quero J, and the Iris study group. Hospitalization rates for respiratory syncytial virus infection in premature infants born during two consecutive seasons. Pediatr Infect Dis J 2001;20:874-9.

11 Joffe S, Lieu TA, Escobar GJ. The critical role of population-based epidemiology in cost-effectiveness research. Pediatrics 2000;105:862-3.

12 The Prevent Study Group. Reduction of respiratory syncytial virus hospitalization among premature infants and infants with bronchopulmonary dysplasia using respiratory syncytial virus immune globin prophylaxis. Pediatrics 1997;99:93-9.

13 The IMPACT-RSV Study Group. Palivizumab, a humanized respiratory syncytial virus monoclonal antibody, reduces hospitalization from respiratory syncytial virus infection in high risk infants. Pediatrics 1998;102:531-7.

14 Storch GA. Humanized monoclonal antibody for prevention of respiratory syncytial virus infection. Pediatrics 1998;102:648-50.

15 American Academy of Pediatrics. Prevention of respiratory syncytial virus infections: indications for the use of palivizumab and update on the use of RSV-IGIV. Pediatrics 1998;102:1211-16.

16 Lucas A, Cole TJ, Gandy GM. Birthweight centiles in preterm infants. Early Hum Dev 1986;13:313-22.

17 Freymuth F, Quibriac M, Petitjean J, et al. Comparison of two new tests for rapid diagnosis of respiratory syncytial virus infections by enzyme-linked immunosorbent assay and immunofluorescence technique. J Clin Microbiol 1986;24:1013-16.

18 Larroque B, Breart G, Kaminski $M$, et al. Survival of very preterm infants: Epipage, a population-based cohort study. Arch Dis Child Fetal Neonatal Ed 2004;89:F139-44.

19 Egreteau L, Pauchard JY, Semama DS, et al. Chronic oxygen dependency in infants born at less than 32 weeks' gestation: incidence and risk factors. Pediatrics 2001; 108:e26.

20 Vik T, Vatten L, Markestad T, et al. Morbidity during the first year of life in small for gestational age infants. Arch Dis Child Fetal Neonatal Ed 1996;75:F33-7.

21 Dupont L, Marret S, Brossard V, et al. A propos of the risk of rehospitalization of low birth weight infants. Arch Pediatr 1997;4:287.

22 Hall CB. Respiratory syncytial virus. In: Feigin RD, Cherry JD, eds. Textbook of pediatric infectious diseases, 4th edn. Philadelphia, PA: WB Saunders Co., 1998:2087

23 Izurieta HS, Thompson WW, Kramarz P, et al. Influenza and the rates of hospitalization for respiratory disease among infants and young children. N Engl J Med 2000;342:1752-3

24 Papadopoulos NG, Moustaki M, Tsolia M, et al. Association of rhinovirus infection with increased disease severity in acute bronchiolitis. Am J Respir Crit Care Med 2002; 165:1285-9. 